\title{
Correspondence
}

\section{Managing suicide risk in primary care}

\author{
05 June 2021
}

We read with interest Professor Morgan's special article on predicting short-term suicide risk. ${ }^{1}$ We are grateful for the mention of the extensive body of evidence suggesting the futility of suicide risk assessments and alleged risk factors including suicidal thoughts and behaviours in predicting suicide risk. We appreciate the statements 'To base assessment of ongoing risk on the individual's mental state during a single interview is clearly likely to be highly unreliable' and 'An important trigger for relapse is stress, particularly stress that has previously been present and has not been resolved'. It is important that the above facts are conveyed to the patient's general practitioner (GP) via the suggested correspondence. However, we wonder about the purpose of the proposed 123-word paragraph ending with the sentence 'Overall, however, the predicted level of suicide risk must still be regarded as significant, requiring vigilance until I next see him/her'. What action is required of the GP when they receive similar letters about almost every patient seen by the mental health services? If the patient requires vigilance for their mental health, would this not best be provided by secondary care mental health services with their array of highly specialist teams and army of experts? What aspects of suicide prevention are the GPs better equipped for than the secondary care mental health services? It is important to acknowledge that it is not possible to reliably predict suicide risk from single consultations. However, it appears the suggested correspondence is unrealistically asking an already overstretched primary care service to pick up responsibility in a specialist area. Furthermore, we would be grateful for any guidance on how to better assess and manage suicide risk during a $10 \mathrm{~min}$ GP consultation than during the $30-60 \mathrm{~min}$ assessment by specialists.

Ann Maria Albert, GPST3, Oxford GPVTS, UK. Email: Annmaria.albert1@nhs.net; Hannah Gallen, GPST1, Reading GPVTS, UK; Misha Gaur, GPST3, Reading GPVTS, UK

\section{Reference}

1 Morgan G. Predicting short-term suicide risk: allowing for ongoing variation in severity of intent. BJPsych Bull 2021; 45, 105-8.

\section{doi:10.1192/bjb.2021.95}

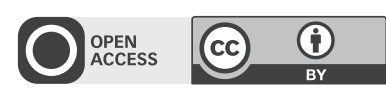

(c) The Author(s), 2021. Published by Cambridge University Press on behalf of the Royal College of Psychiatrists. This is an Open Access article, distributed under the terms of the Creative Commons Attribution licence (https://creativecommons.org/licenses/by/4.0/), which permits unrestricted re-use, distribution, and reproduction in any medium, provided the original work is properly cited.

\section{Author's reply:}

17 June

I am grateful to Drs Albert, Gallen and Gaur for their interest in my paper. Unfortunately they appear to have misunderstood some major points which I make. I certainly do not suggest that the assessment of suicidal thoughts is futile in short-term prediction of suicide. I argue exactly the opposite, presenting evidence that provided this is carried out correctly and appropriately, it should have significant predictive value.

What is more, I do not in any way suggest that ongoing care of suicidal patients should be handed back to the general practitioner (GP), certainly not before their problems have been resolved. My suggested letters are meant as clinical summaries which should be sent routinely to GPs by any psychiatric team as part of good ongoing clinical care. They do not mean, in any way, that the secondary service thereby should relinquish ongoing clinical care of their patients before treatment is complete.

How to maintain good ongoing supportive care of patients who have experienced a suicidal crisis is an important clinical challenge. My paper considers how the psychiatrist might attempt to achieve this, by emphasising concern to provide the form of help which would be most acceptable to the patient, and to which he/she would readily turn should the crisis recur.

Gethin Morgan, Emeritus Professor of Mental Health, University of Bristol, Bristol, UK. Email: hilary.howard@blueyonder.co.uk

doi:10.1192/bjb.2021.96

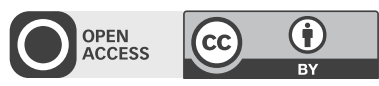

(c) The Author(s), 2021. Published by Cambridge University Press on behalf of the Royal College of Psychiatrists. This is an Open Access article, distributed under the terms of the Creative Commons Attribution licence (https://creativecommons.org/licenses/by/4.0/), which permits unrestricted re-use, distribution, and reproduction in any medium, provided the original work is properly cited.

\section{Fluctuation of suicide intent and other matters in psychosocial assessment post self-harm}

Professor Morgan's article rightly focuses on the fluctuations in suicidal intent among mentally ill people undergoing the various crises and vicissitudes of life. He emphasises the importance of repeated assessments, rather than relying on the initial one, to accommodate these fluctuations in intent.

He appears to have given up on prospects of predicting longer-term suicide risk but has not commented on the emerging body of evidence suggesting the effectiveness of combining an app-based questionnaire with inflammatory biomarkers such as interleukin subtypes, SAT1 and Toll-like receptor subtypes. ${ }^{1}$ These biomarkers probably reflect the degree of underlying stress which Professor Morgan describes, with some quantitative features provided in addition. These types of hybrid assessments should cover both the short- and longer-term risks but will not predict when (or under what circumstances) the lethal behaviour could take place.

Consequently, mitigation needs simple strategies such as Dr Cole-King's suicide safety plan, a brief document co-produced with the patient, held by the patient and carer, describing what to do and who to contact if suicidal intent reaches a climax. ${ }^{2}$

Brief hybrid assessments might also be less intrusive and distressing to patients compared with the standard 'psychosocial assessment' carried out in emergency room settings, typically by junior psychiatric liaison staff and often under time pressure (including the $4 \mathrm{~h}$ wait and expectations of prompt bed clearance and discharge as the person is deemed 'medically fit'). Often 
both the assessor and patient are aware that this is likely to be the only contact between them, further reducing the likelihood of frank disclosure of trauma and abuse; this is strongly associated with invalid assessments and completed suicide in the future. ${ }^{3}$

Patients also find repeated disclosures of personal details to multiple mental health staff frustrating and traumatic, ${ }^{4}$ along the lines of 'why don't you look up the notes before speaking to me?'. Similar to the experience of repeated police interviews under implied caution ('anything you say might be used for a future Mental Health Act assessment'), patients are (perhaps rightly) suspicious that the assessors are looking for discrepancies in the history to undermine the reliability of the person's account leading to suicidal thinking and/or self-harming behaviour, thereby making it easier to discharge (or dismiss) the patient seeking help.

Professor Morgan touches on in-patient ('never event') suicides, ${ }^{5,6}$ mainly involving patients who have either absconded or been given planned home leave, as major improvements to ward design (including shaving off door edges and securing windows, door handles and toilet equipment) have now taken place. He does not, however, suggest practical changes in ward policy, for example, the potential benefit of a face-to-face review within $24 \mathrm{~h}$ of being placed on home leave in order to check on basic needs (elegantly summarised by Maslow), as well as potential toxic relationships with close family members, who might be either over-controlling or otherwise pessimistic on the prospects of the patient moving from being a burden (a variation on therapeutic nihilism and malignant alienation, not often discussed in the literature).

Finally, the issue that $\mathrm{I}$, as a clinician, struggle most with when debriefing assessors or looking at longer-term suicide mitigation is that suicide risk assessment is used primarily as a defensive tool by the assessor, possibly aided by the patient, who does not wish to upset the assessor or get him/her into trouble in the future. So, the 'protective factors' often highlighted in the assessment are documented without due diligence on how stable or permanent these are.

On occasion, a suicidal person will 'blurt out' a suicide plan he/she has been considering. Often, this communication is with a staff member of low rank, for example, a ward domestic or student nurse, simply based on their compassionate nature and their not being part of the 'assessment brigade'. Typically, these patients will subsequently deny that they will carry out this plan, and at times they will deny ever having disclosed such a plan, but, given the circumstance or opportunity, they may use the plan. Alternatively, a person who has failed with a plan will deny wanting to repeat the action (for example, an overdose) but could use this as a learning experience to organise a variation or plan more violent methods such as jumping or hanging.

As Professor Morgan rightly states, an assessor needs to compassionately (and non-judgementally) ask whether alternative means have been considered following a failed suicide attempt. This is genuinely hard work and especially emotionally draining. Therefore, it is essential for staff assessing suicidal patients to be debriefed supportively and given sufficient time off (at least undertaking other duties) to regain their emotional composure.

Prasanna de Silva, Cumbria, Northumberland, Tyne and Wear NHS Trust, UK. Email: Prasanna.deSilva@entw.nhs.uk

\section{References}

1 Niculescu AB, Levey DF, Phalen PL, Le-Niculescu H, Dainton HD, Jain N, et al. Understanding and predicting suicidality using a combined genomic and clinical risk assessment approach. Mol Psychiatry 2015; 20(11): 1266-85.

2 Cole-King A, Green G, Gask L, Hines K, Platt S. Suicide mitigation: a compassionate approach to suicide prevention. Adv Psychiatr Treat 2013; 19: 276-83.

3 Doyle C, Lennox L, Bell D. A systematic review of evidence on the links between patient experience and clinical safety and effectiveness. BMJ Open 2013; 3: e001570.

4 Hunter C, Chantler K, Kapur N, Cooper J. Service user perspectives on psychosocial assessment following self-harm and its impact on further help-seeking: a qualitative study. J Affect Disord 2013; 145: 315-23.

5 Bowers L, Banda T, Nijman H. Suicide inside: a systematic review of inpatient suicides. J Nerv Ment Dis 2010; 198(5): 315-28.

6 Hunt IM, Windfuhr K, Swinson N, Shaw J, Appleby L, Kapur N, et al. Suicide amongst psychiatric in-patients who abscond from the ward: a national clinical survey. BMC Psychiatry 2010; 10: 14.

doi:10.1192/bjb.2021.97

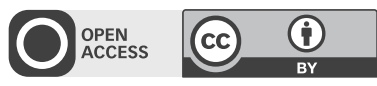

(c) The Author(s), 2021. Published by Cambridge University Press on behalf of the Royal College of Psychiatrists. This is an Open Access article, distributed under the terms of the Creative Commons Attribution licence (https://creativecommons.org/ licenses/by/4.0/), which permits unrestricted re-use, distribution, and reproduction in any medium, provided the original work is properly cited.

\section{Response to Dr de Silva's letter}

02 December 2020

Dr de Silva's wide-ranging review of suicide prediction strategies is very welcome: it includes a number of useful new ideas on how our predictive efforts can be taken forwards. I do not wish to take issue with any of them. My own paper, however, focuses more narrowly on two specific issues. The first highlights the way in which ongoing variation in severity of intent, usually due to the random and unpredictable occurrence of stress-related events, can confound our predictive efforts, and I suggest how we might circumvent this. The second aims to show that, in spite of attempts to dismiss its value, the assessment of suicidal ideation can have a useful role in the prediction process, provided it is applied correctly and used appropriately. My approach is in the nature of risk assessment, which has been criticised by some as being too dependent on negative issues. I hope I have shown that by helping to identify future hazards and so anticipate ways of dealing with them, this is not just a negative process. A capable clinician should surely be able to ensure that such assessment does not compromise the establishment of a good trusting relationship with the patient. My overall hope for the future of suicide prevention is that polarised views, in which different approaches are seen as either good or flawed, will not prevail. Good points from each and every approach can then be incorporated into an overall synthesis of preventive strategy that can be used in clinical practice.

Gethin Morgan, Emeritus Professor of Mental Health, University of Bristol, Bristol, UK. Email: hilary.howard@blueyonder.co.uk

doi:10.1192/bjb.2021.98

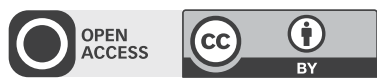

(c) The Author(s), 2021. Published by Cambridge University Press on behalf of the Royal College of Psychiatrists. This is an Open Access article, distributed under the terms of the Creative Commons Attribution licence (https://creativecommons.org/ licenses/by/4.0/), which permits unrestricted re-use, distribution, and reproduction in any medium, provided the original work is properly cited. 